\title{
The Solid Phase Photolysis and Radiolysis of Ethylene at 20 to $77 \mathrm{~K}^{*}$
}

\author{
R. Gorden, Jr., and P. Ausloos \\ Institute for Materials Research, National Bureau of Standards, Washington, D.C. 20234
}

(January 11, 1971)

\begin{abstract}
Films of ethylene condensed onto a cold finger maintained at $20 \mathrm{~K}$ were irradiated with photons whose energy ranged from 8.4 to $21.2 \mathrm{eV}$. At the higher photon energies the relative yields of products compare well with those seen in the radiolysis of solid ethylene. Experiments on $\mathrm{CH}_{2} \mathrm{CD}_{2}$ demonstrate that in the photolysis hydrogen is mainly formed by the elimination processes $\mathrm{CH}_{2} \mathrm{CD}_{2}^{*} \rightarrow \mathrm{H}_{2}\left(\mathrm{D}_{2}\right)$ $+\mathrm{C}_{2} \mathrm{D}_{2}\left(\mathrm{C}_{2} \mathrm{H}_{2}\right)$ and $\mathrm{CH}_{2} \mathrm{CD}_{3}^{*} \rightarrow \mathrm{HD}+\mathrm{C}_{2} \mathrm{HD}$. The relative probabilities of these three processes are independent of the energy of the incident photons from 8.4 to $11.6 \mathrm{eV}$ and are within experimental error identical to those observed in earlier gas phase photolysis experiments. Relative to acetylene, cyclobutane is a minor product at $8.4 \mathrm{eV}$ but increases by an order of magnitude at higher energies where ions play a role. Cyclobutane, 1-butene and methylcyclopropane formed upon irradiation of frozen $\mathrm{C}_{2} \mathrm{H}_{4}-\mathrm{C}_{2} \mathrm{D}_{4}$ mixtures consisted mainly of $\mathrm{C}_{4} \mathrm{D}_{8}, \mathrm{C}_{4} \mathrm{D}_{4} \mathrm{H}_{4}$, and $\mathrm{C}_{4} \mathrm{H}_{8}$. Plausible mechanisms which may account for the formation of the latter products are examined. In the solid phase as in the gas phase the relative importance of $\mathrm{H}$-atom production is seen to increase with increasing photon energy. Cyclopropane, apparently formed by insertion of $\mathrm{CH}_{2}$ into $\mathrm{C}_{2} \mathrm{H}_{4}$, is observed as a product at all wavelengths in the photolysis, and in the radiolysis.
\end{abstract}

Key words: Ethylene; free radical reactions; ion-molecule reactions; photolysis; polymerization; radiolysis.

\section{Introduction}

The condensed phase photolysis of simple olefins has not as yet been investigated in detail. Only one experiment dealing with ethylene ( $8.4 \mathrm{eV}$ photons, $36 \mathrm{~K}$ ) has been discussed $[1]^{1}$ in the literature. It was suggested that the products (1- $\mathrm{C}_{4} \mathrm{H}_{8}$ and methylcyclopropane) observed in the latter experiment were formed by the addition of ethylidene radicals to ethylene. The condensed phase radiolysis of olefins, on the other hand, has been investigated extensively $[2,3]$. In the radiolysis studies on ethylene, 1-butene was noted as a major product and was thought to be produced by addition of an ethylene ion to ethylene. Hexenes, octenes, and decenes which were also observed were suggested to be formed by subsequent additions of product ions to ethylene. Isotopic analysis of the $\mathrm{C}_{4}, \mathrm{C}_{6}$, and $\mathrm{C}_{8}$ products formed in the radiolysis of $\mathrm{C}_{2} \mathrm{H}_{4}-\mathrm{C}_{2} \mathrm{D}_{4}$ did reveal [3c] that these products are indeed mainly formed by consecutive additions to form polymer molecules containing deuterium in multiples of four.

The purpose of the study reported here is to explore the processes occurring in the solid phase irradiation of ethylene more fully. The photolysis has been investigated at four different energies. At the lowest

*This research was supported by the Atomic Energy Commission.

' Figures in brackets indicate the literature references at the end of this paper. of these energies $(8.4 \mathrm{eV})$ ionic processes can be assumed to be relatively unimportant. At the highest energy $(21.2 \mathrm{eV})$ it is likely that a large fraction of photons absorbed lead to the formation of ethylene parent ions. Therefore, this series of experiments may allow us to contrast the product formation which follows ionization with that associated with neutral excited molecule formation. In addition, certain aspects of the solid phase radiolysis have been reinvestigated.

Finally deuterium labeling has been utilized in several experiments in order to examine in more detail the modes of formation of certain products.

\section{Experimental Procedure}

The apparatus and procedure for the solid phase photolysis and radiolysis experiments have been described previously $[4,5]$. A detailed description of the rare gas resonance light sources has also been given in an earlier report [6]. The NBS 20,000 Curie cobalt-60 source was used for the gamma radiolysis experiments. One radiation experiment with $21.2 \mathrm{eV}$ photons was carried out with a helium resonance lamp provided with an aluminum window [6]. Isotopic analyses of hydrocarbon products were carried out on a high resolution mass spectrometer using a low energy $(12-15 \mathrm{eV})$ electron beam. 


\section{Results}

The relative yields of the major products which were measured are given in table 1. Only the sum of the hexene yields is given in the last column. At least eight different $\mathrm{C}_{6} \mathrm{H}_{12}$ isomers are formed in the radiolysis as well as in the photolysis at all wavelengths. No attempt was made to analyze for products with molecular weights higher than those of the $\mathrm{C}_{6}$ products. In the photolysis of $\mathrm{C}_{2} \mathrm{H}_{4}-\mathrm{C}_{2} \mathrm{D}_{4}$ mixtures at $11.6-11.8 \mathrm{eV}$, 70 percent of the hexene mixture consisted of $\mathrm{C}_{6} \mathrm{D}_{12}$, $\mathrm{C}_{6} \mathrm{D}_{8} \mathrm{H}_{4}, \mathrm{C}_{6} \mathrm{D}_{4} \mathrm{H}_{8}$, and $\mathrm{C}_{6} \mathrm{H}_{12}$.

Two products, cyclopropene and methylcyclopropene which were previously reported to be formed in the $8.4 \mathrm{eV}$ photolysis of $\mathrm{C}_{2} \mathrm{H}_{4}$ at $36 \mathrm{~K}$ were not observed in our study. In accord with the observation made in the previous investigation, there was a compound which eluted from a squalane column between $i-\mathrm{C}_{4} \mathrm{H}_{10}$ and $1-\mathrm{C}_{4} \mathrm{H}_{8}$. However, mass spectrometric analysis indicated it to be a $\mathrm{C}_{4} \mathrm{H}_{4}$ isomer rather than methylcyclopropene $\left(\mathrm{C}_{4} \mathrm{H}_{6}\right)$ as suggested previously. The yield of the $\mathrm{C}_{4} \mathrm{H}_{4}$ product was seen to increase relative to that of the other products when the irradiation time was increased. It may, therefore, be ascribed to secondary photolysis of a product, probably acetylene. Two other products, cyclobutene and an unknown $\mathrm{C}_{4} \mathrm{H}_{6}$ product were also seen to increase with the percent conversion of ethylene. At the lowest percent decomposition $(0.02 \%)$, the yields of $\mathrm{C}_{4} \mathrm{H}_{4}$ and cyclobutene were less than 1 percent of that of acetylene. It is of interest that the cyclobutene product formed in the irradiation of a $\mathrm{C}_{2} \mathrm{H}_{4}-\mathrm{C}_{2} \mathrm{D}_{4}$ mixture with 8.4 $\mathrm{eV}$ photons consisted mainly ( $\sim 90 \%$ ) of $\mathrm{C}_{4} \mathrm{D}_{6}, \mathrm{C}_{4} \mathrm{D}_{4} \mathrm{H}_{2}$, $\mathrm{C}_{4} \mathrm{D}_{2} \mathrm{H}_{4}$, and $\mathrm{C}_{4} \mathrm{H}_{6}$. Such a distribution is consistent with a mechanism involving the addition of an acetylene molecule to ethylene.

In pure ethylene, the relative yields of all products listed in table 1 showed only minor $(\sim 10 \%)$ variations when the percent conversion was varied over a 10 -fold range (from 0.02 to $0.2 \%$ ). The precision with which the relative yields are measured is approximately 10 percent for products whose yields are 1 percent or more of that of acetylene. For the other products the precision is estimated at 10 to 20 percent.

Quantum yields were not determined in any of the photolysis experiments. However, at any particular wavelength the yield of acetylene per unit time was seen to change by not more than 20 percent from one experiment to the next.

Besides the isotopic analyses referred to above and in tables 2, 3, and 4, several other products have been analyzed isotopically. Cyclopropane in the $11.6-11.8 \mathrm{eV}$ photolysis of $\mathrm{C}_{2} \mathrm{H}_{4}-\mathrm{C}_{2} \mathrm{D}_{4}(1: 1)$ at $20 \mathrm{~K}: \mathrm{C}_{3} \mathrm{H}_{6}-100$; $\mathrm{C}_{3} \mathrm{DH}_{5}-25, \mathrm{C}_{3} \mathrm{D}_{2} \mathrm{H}_{4}-98 ; \mathrm{C}_{3} \mathrm{D}_{3} \mathrm{H}_{3}-16 ; \mathrm{C}_{3} \mathrm{D}_{4} \mathrm{H}_{2}-97$; $\mathrm{C}_{3} \mathrm{D}_{5} \mathrm{H}-11$ and $\mathrm{C}_{3} \mathrm{D}_{6}-89$. Cyclobutane in the $10.0 \mathrm{eV}$ photolysis of $\mathrm{C}_{2} \mathrm{H}_{4}-\mathrm{C}_{2} \mathrm{D}_{4}(1: 1)$ at $20 \mathrm{~K}: \mathrm{C}_{4} \mathrm{H}_{8}-120$; $\mathrm{C}_{4} \mathrm{DH}_{9}-6 ; \mathrm{C}_{4} \mathrm{D}_{3} \mathrm{H}_{5}-15 ; \mathrm{C}_{4} \mathrm{D}_{4} \mathrm{H}_{4}-140 ; \mathrm{C}_{4} \mathrm{D}_{5} \mathrm{H}_{3}-10$; $\mathrm{C}_{4} \mathrm{D}_{6} \mathrm{H}_{2}-16 ; \mathrm{C}_{4} \mathrm{D}_{7} \mathrm{H}-11$, and $\mathrm{C}_{4} \mathrm{D}_{8}-110$.

\section{Discussion}

Table 1 shows the relative yields of products formed in the photolysis of ethylene at $20 \mathrm{~K}$ with $8.4,10.0$, 11.6-11.8, and $21.2 \mathrm{eV}$ photons, as well as in the gamma-radiolysis at $77 \mathrm{~K}$. In the gas phase, the ionization energy of ethylene is $10.5 \mathrm{eV}$; [7] the ionization energy in the solid phase is unknown, and may be 1-2

TABLE 1. Products in the solid phase photolysis and radiolysis of $\mathrm{C}_{2} \mathrm{H}_{4}$

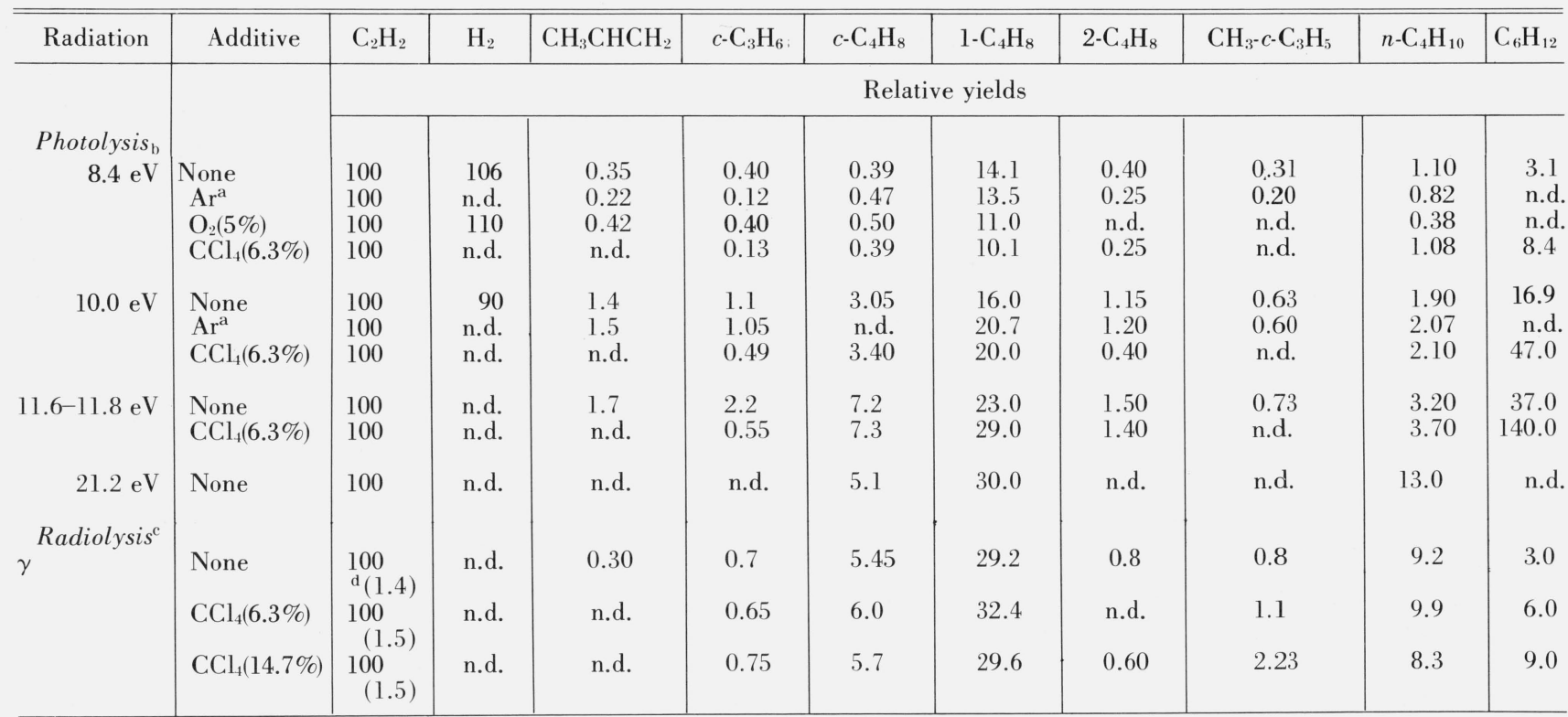

\footnotetext{
${ }^{\mathrm{a}} \mathrm{Ar} / \mathrm{C}_{2} \mathrm{H}_{4}=50$.

${ }^{\mathrm{b}} T=20^{\prime} \mathrm{K}$.

${ }^{\mathrm{c}} T=77^{\prime} \mathrm{K}$.

${ }^{\mathrm{d} V}$ alues in parenthesis are $G$-values (molecules of acetylene formed per $100 \mathrm{eV}$ ).
} 
TABLE 2. Hydrogen and acetylene from $\mathrm{C}_{2} \mathrm{H}_{4}-\mathrm{C}_{2} \mathrm{D}_{4}(1: 1)$ at $20 \mathrm{~K}$

\begin{tabular}{l|c|c|c|c|c|c}
\hline \hline \multicolumn{1}{c}{} & \multicolumn{7}{c}{ Percent distributions } \\
\hline \multirow{2}{*}{$8.4 \mathrm{eV}$} & $\mathrm{C}_{2} \mathrm{H}_{2}$ & $\mathrm{C}_{2} \mathrm{HD}$ & $\mathrm{C}_{2} \mathrm{D}_{2}$ & $\mathrm{H}_{2}$ & $\mathrm{HD}$ & $\mathrm{D}_{2}$ \\
\cline { 2 - 7 } $11.6-11.8 \mathrm{eV}$ & 59.0 & 7.0 & 34.0 & 61.0 & 3.0 & 36.0 \\
$\gamma$-ray & 60.5 & 5.0 & 34.5 & 62.0 & 3.5 & 34.5 \\
\hline
\end{tabular}

TABLE 3. Acetylene and hydrogen in the photolysis and radiolysis of $\mathrm{CH}_{2} \mathrm{CD}_{2}$

\begin{tabular}{|c|c|c|c|c|c|c|c|}
\hline & $\mathrm{C}_{2} \mathrm{H}_{2}$ & $\mathrm{C}_{2} \mathrm{HD}$ & $\mathrm{C}_{2} \mathrm{D}_{2}$ & $\mathrm{D}_{2}$ & HD & $\mathrm{H}_{2}$ \\
\hline & & \multicolumn{6}{|c|}{ Percent distribution } \\
\hline \multirow{3}{*}{$\begin{array}{c}\text { Photolysis } \\
8.4 \mathrm{eV}\end{array}$} & & & & & & & \\
\hline & Gas & 11.0 & 63.9 & 25.1 & 16.9 & 41.1 & 42.0 \\
\hline & Soma & 23.1 & 37.3 & 59.0 & & 50.0 & \\
\hline \multirow[t]{2}{*}{$10.0 \mathrm{eV}$} & Gas & 10.5 & 63.5 & 26.0 & 17.6 & 40.6 & 41.8 \\
\hline & Solid & 21.7 & 41.7 & 36.6 & 20.6 & 39.1 & 39.6 \\
\hline \multirow[t]{2}{*}{$11.6-11.8 \mathrm{eV}$} & Gas & 11.1 & 62.2 & 26.7 & 16.7 & 41.5 & 41.8 \\
\hline & Solid & 14.1 & 53.4 & 32.5 & 16.8 & 41.0 & 42.2 \\
\hline \multirow{3}{*}{$\begin{array}{c}\text { Radiolysis } \\
\gamma\end{array}$} & & & & & & & \\
\hline & Gas & 12.7 & 65.1 & 22.2 & 15.1 & 46.4 & 38.5 \\
\hline & Solid & 17.7 & 52.7 & 29.6 & 26.5 & 31.0 & 42.5 \\
\hline
\end{tabular}

Pressure in gas phase experiments: 10 torr.

Temperature in solid phase experiments: $20 \mathrm{~K}$.

TABLE 4. 1-Butene yields from $\mathrm{C}_{2} \mathrm{H}_{4}-\mathrm{C}_{2} \mathrm{D}_{4}(1: 1)$

\begin{tabular}{l|r|r|r}
\hline \hline & & & \\
& $\gamma$-Rays & $10 \mathrm{eV}$ Photons & $8.4 \mathrm{eV}$ Photons \\
& $77 \mathrm{~K}$ & $20 \mathrm{~K}$ & $20 \mathrm{~K}$ \\
\cline { 2 - 4 } & & & \\
$\mathrm{C}_{4} \mathrm{H}_{8}$ & 100 & 100 & 100 \\
$\mathrm{C}_{4} \mathrm{H}_{7} \mathrm{D}$ & 11 & 12 & 14 \\
$\mathrm{C}_{4} \mathrm{H}_{6} \mathrm{D}_{2}$ & 5 & 7 & 11 \\
$\mathrm{C}_{4} \mathrm{H}_{5} \mathrm{D}_{3}$ & 17 & 22 & 18 \\
$\mathrm{C}_{4} \mathrm{H}_{4} \mathrm{D}_{4}$ & 122 & 125 & 110 \\
$\mathrm{C}_{4} \mathrm{H}_{3} \mathrm{D}_{5}$ & 8 & 9 & 11 \\
$\mathrm{C}_{4} \mathrm{H}_{2} \mathrm{D}_{6}$ & 3 & 4 & 5 \\
$\mathrm{C}_{4} \mathrm{HD}_{7}$ & 8 & 8 & 10 \\
$\mathrm{C}_{4} \mathrm{D}_{8}$ & 39 & 39 & 35 \\
\hline
\end{tabular}

$\mathrm{eV}$ lower than the gas phase value [8]. Most likely, ionization is unimportant in the solid phase photolysis at $8.4 \mathrm{eV}$, which is more than $2 \mathrm{eV}$ below the gas phase ionization energy, but in all other experiments shown in table 1 , ionic processes undoubtedly play a major role. In the gas phase the photoionization quantum yield of $\mathrm{C}_{2} \mathrm{H}_{4}$ at pressures around 20 torr is approximately 0.2 and 0.9 at 11.6 and $16.8 \mathrm{eV}$ respectively $[6,9]$. The photoionization quantum yield of $\mathrm{C}_{2} \mathrm{H}_{4}$ in the solid phase is not known and may be expected to differ from the gas phase values. Keeping in mind the lack of knowledge concerning the ionization processes in the solid phase, the modes of formation of some of the major products will now be discussed by considering both neutral and ionic mechanisms.

\subsection{The Formation of Acetylene and Hydrogen}

In the solid phase radiolysis and photolysis of ethylene, the major products formed at all energies are acetylene and hydrogen. It is seen, first of all, from the results obtained with $\mathrm{C}_{2} \mathrm{D}_{4}: \mathrm{C}_{2} \mathrm{H}_{4}(1: 1)$ mixtures (table 2) that in the solid phase essentially all the hydrogen and acetylene are produced in molecular elimination processes or by geminate disproportionation reactions (which in such a mixture lead to the formation of $\mathrm{C}_{2} \mathrm{H}_{2}$ and $\mathrm{C}_{2} \mathrm{D}_{2}, \mathrm{D}_{2}$, and $\mathrm{H}_{2}$, exclusively). Although in the gas phase radiolysis $\mathrm{C}_{2} \mathrm{H}_{2}$ may be formed by charge transfer [10] from $\mathrm{C}_{2} \mathrm{H}_{2}^{+}$to $\mathrm{C}_{2} \mathrm{H}_{4}$ such a mechanism can be discounted in the condensed phase because of the reduced fragmentation of parent ions with increase in density [11]. Therefore, in the condensed phase photolysis and radiolysis, acetylene is tentatively assumed to be formed via decomposition of neutral excited ethylene molecules formed by direct excitation and by neutralization of the parent ion.

In the gas phase, the excited ethylene formed by absorption of 8.4 to $11.8 \mathrm{eV}$ photons, dissociates as follows $[9,12]$ :

$$
\begin{aligned}
\mathrm{C}_{2} \mathrm{H}_{4}^{*} & \rightarrow \mathrm{CHCH}+\mathrm{H}_{2} \\
& \rightarrow \mathrm{CH}_{2} \mathrm{C}+\mathrm{H}_{2} \\
& \rightarrow \mathrm{C}_{2} \mathrm{H}_{2}+2 \mathrm{H}
\end{aligned}
$$

At atmospheric pressure the excited vinyl radicals formed as intermediates in process 3 dissociate at wavelengths below $147 \mathrm{~nm}(8.4 \mathrm{eV})$. Only at wavelengths above $155 \mathrm{~nm}$, have stable $\mathrm{CH}_{2} \mathrm{CH}$ radicals been noted [13]. In the condensed phase photolysis and radiolysis all, or at least a considerable fraction, of the vinyl radicals may be expected to be stabilized. Actually vinyl radicals have been observed by ESR in the liquid phase radiolysis of ethylene [3f].

The occurrence of process 2 has been established from the isotopic distributions of the hydrogen products [12] formed in the photolysis of $\mathrm{CD}_{2} \mathrm{CH}_{2}$. The relative importance of processes 4 through 6 (i.e., 1 and 2) are approximately $0.41: 0.42: 0.17$ in the gas phase, invariant with energy:

$$
\begin{aligned}
\mathrm{CD}_{2} \mathrm{CH}_{2}^{*} & \rightarrow \mathrm{CDCH}+\mathrm{HD} \\
& \rightarrow \mathrm{CD}_{2} \mathrm{C}+\mathrm{H}_{2} \\
& \rightarrow \mathrm{CH}_{2} \mathrm{C}+\mathrm{D}_{2}
\end{aligned}
$$

The gas phase results are compared with the analogous results obtained in the solid phase experiments in table 3. It is seen that the isotopic composition of the hydrogen fractions in the solid phase photolysis experiments closely resemble those observed in the gas phase.

Furthermore, in the solid phase photolysis experiments at 8.4 and $10.0 \mathrm{eV}$, there is a near equality between the yields of hydrogen and acetylene (table 1); 
in fact, in the photolysis of $\mathrm{CD}_{2} \mathrm{CH}_{2}$ the yields of the various complementary isotopically labeled hydrogen and acetylene species match roughly $\left(\mathrm{C}_{2} \mathrm{H}_{2} \approx \mathrm{D}_{2}\right.$, $\mathrm{C}_{2} \mathrm{HD} \approx \mathrm{HD}, \mathrm{C}_{2} \mathrm{D}_{2} \approx \mathrm{H}_{2}$ ). This indicates that in these experiments, decomposition of vinyl radicals is indeed not important and that reaction 7 , which in the gas phase accounts for a considerable fraction of the CHCD yield [12], occurs via an excited vinyl radical intermediate.

$$
\mathrm{CH}_{2} \mathrm{CD}_{2}^{*} \rightarrow \mathrm{CHCD}+\mathrm{H}+\mathrm{D}
$$

Assuming that in the solid phase experiments the disproportionation reaction

$$
\left[\mathrm{CH}_{2} \mathrm{CD}\left(\text { or } \mathrm{CD}_{2} \mathrm{CH}\right)+\mathrm{D}(\text { or } \mathrm{H})\right] \rightarrow \mathrm{CHCD}+\mathrm{HD}
$$

occurs with a low probability, it may be concluded that molecular hydrogen elimination processes occur via the same excited state in the gas as in the solid phase independent of the energy of the photon. In gas phase photolysis experiments the yield of acetylene is always considerably higher than that of "molecular" hydrogen $\left(\mathrm{C}_{2} \mathrm{H}_{2} / \mathrm{H}_{2}=2.8\right.$ at $\left.10 \mathrm{eV}\right)$. The occurrence of process 3 (process 7 in the case of $\mathrm{CH}_{2} \mathrm{CD}_{2}$ ) accounts for this, as is clearly illustrated by the fact that in all gas phase $\mathrm{CH}_{2} \mathrm{CD}_{2}$ experiments the abundance of CHCD in the acetylene fraction is considerably higher than that of $\mathrm{HD}$ in the hydrogen fraction. In the solid phase photolysis at $11.6-11.8 \mathrm{eV}$ and in the radiolysis the abundance of $\mathrm{C}_{2} \mathrm{HD}$ in the acetylene fraction is somewhat higher than that of HD in the hydrogen fraction indicating that at these energies reaction 7 may occur. Disproportionation reactions involving $\mathrm{CH}_{2} \mathrm{CD}$ or $\mathrm{CD}_{2} \mathrm{CH}$ and any other radical are however a more likely source of the excess $\mathrm{C}_{2} \mathrm{HD}$ in the solid phase.

The absence of HD in the photolysis and radiolysis of $\mathrm{C}_{2} \mathrm{D}_{4}: \mathrm{C}_{2} \mathrm{H}_{4} \quad(1: 1)$ mixtures demonstrates that if $\mathrm{H}(\mathrm{D})$ atoms are indeed eliminated in the primary process they do not combine with other $\mathrm{H}$ atoms to form hydrogen in these experiments. The most probable fate of these $\mathrm{H}$ atoms especially if they are formed with excess kinetic energy, is addition to ethylene to form ethyl radicals:

$$
\mathrm{H}+\mathrm{C}_{2} \mathrm{H}_{4} \rightarrow \mathrm{C}_{2} \mathrm{H}_{5}
$$

The $\mathrm{C}_{2} \mathrm{H}_{5}$ radicals thus formed will combine or disproportionate with other radicals in situ or during warm-up. $n$-Butane is one of the products which may originate from such a free radical combination reaction. The fact that the yield of $n$-butane relative to that of acetylene is quenched by oxygen at $8.4 \mathrm{eV}$ (table 1 ) supports this view. The relative yield of $n$-butane is seen to increase with the energy of the photon, indicating that the $\mathrm{H}$-atom production becomes relatively more important at high energies. The highest yield of $n$-butane is observed in the $21.2 \mathrm{eV}$ photon irradiation and in the radiolysis. Increasing $\mathrm{H}$-atom production with increasing energy has also been noted in the gas phase photolysis of ethylene $[9,12]$, and is a general trend seen in the photolysis of other hydrocarbons [14].

\subsection{The Formation of $\mathrm{C}_{4} \mathrm{H}_{8}$ Products}

In the gas phase radiolysis of ethylene and in the photolysis at energies above the ionization energy, the ethylene parent ion reacts with ethylene to form $\mathrm{C}_{4} \mathrm{H}_{8}^{+}$ ions [15]:

$$
\begin{aligned}
\mathrm{C}_{2} \mathrm{H}_{4}^{+}+\mathrm{C}_{2} \mathrm{H}_{4} \rightarrow \mathrm{C}_{4} \mathrm{H}_{8}^{+} & k_{13}=8.3 \\
\times & \times 10^{-10} \mathrm{~cm}^{3} / \text { molecule-s. }
\end{aligned}
$$

In the presence of a charge acceptor (CA) such as $\left(\mathrm{CH}_{3}\right)_{2} \mathrm{NH}$ or $\mathrm{NO}$, the $\mathrm{C}_{4} \mathrm{H}_{8}^{+}$ions have been shown to react to form $\mathrm{C}_{4} \mathrm{H}_{8}$ products [16]

$$
\mathrm{C}_{4} \mathrm{H}_{8}^{+}+\mathrm{CA} \rightarrow \mathrm{C}_{4} \mathrm{H}_{8}+\mathrm{CA}^{+}
$$

whose structures are assumed to correspond to the structures of the precursor $\mathrm{C}_{4} \mathrm{H}_{8}^{+}$ions. In the gas phase at pressures of 100 torr or less, reaction sequence 10-11 leads to the formation of 2-butene and isobutene; the relative amounts of these isomeric $\mathrm{C}_{4} \mathrm{H}_{8}$ products depend on the energy in the $\mathrm{C}_{4} \mathrm{H}_{8}^{+}$ion [17]. As the pressure is raised, for example, the formation of iso- $\mathrm{C}_{4} \mathrm{H}_{8}$ (i.e., iso- $\mathrm{C}_{4} \mathrm{H}_{8}^{+}$) is quenched. If reaction 10 can compete with neutralization of the $\mathrm{C}_{2} \mathrm{H}_{4}^{+}$ions in the solid phase, it is possible that the resulting $\mathrm{C}_{4} \mathrm{H}_{8}^{+}$ ions might lead to the formation of $\mathrm{C}_{4} \mathrm{H}_{8}$ products, through neutralization of the ion:

$$
\mathrm{C}_{4} \mathrm{H}_{8}^{+}+e \rightarrow \mathrm{C}_{4} \mathrm{H}_{8}
$$

It has actually been suggested before [3c] that in the solid phase radiolysis reaction 10 followed by 12 might account for the formation of 1-butene.

The results given in table 1 show that 1 -butene is the most important $\mathrm{C}_{4} \mathrm{H}_{8}$ product in all the solid phase experiments. More than 80 percent of the 1-butene formed in the photolysis and radiolysis of $\mathrm{C}_{2} \mathrm{D}_{4}-\mathrm{C}_{2} \mathrm{H}_{4}$ (1:1) mixtures (table 4) consists of $\mathrm{C}_{4} \mathrm{H}_{8}, \mathrm{C}_{4} \mathrm{H}_{4} \mathrm{D}_{4}$, and $\mathrm{C}_{4} \mathrm{D}_{8}$. That is, 1-butene seems to be formed mainly by the combination of two $\mathrm{C}_{2} \mathrm{H}_{4}\left(\mathrm{C}_{2} \mathrm{D}_{4}\right)$ units.

As mentioned above, in the gas phase very little 1-butene is formed in reaction sequence 10-11; isomerization of the $\mathrm{C}_{4} \mathrm{H}_{8}^{+}$ions formed in reaction 10 to the $1-\mathrm{C}_{4} \mathrm{H}_{8}^{+}$structure is evidently an improbable process under those conditions. The fact that the yield of 1-butene is relatively large in the $8.4 \mathrm{eV}$ photolysis where ionization is presumably unimportant, and furthermore undergoes a relatively small increase with increasing energy, seems to indicate that the 1butene is at least in part formed through a nonionic mechanism. A plausible mechanism which would lead to the observed isotopic distribution in the $\mathrm{C}_{2} \mathrm{H}_{4}-\mathrm{C}_{2} \mathrm{D}_{4}$ $(1: 1)$ experiment would be $\mathrm{H}$ atom elimination from ethylene and addition of the hot $\mathrm{H}$-atom to a neighboring ethylene molecule (reaction 9), followed by a recombination in the cage of the two radicals (reaction 13).

$$
\left[\mathrm{CH}_{2} \mathrm{CH}+\mathrm{CH}_{2} \mathrm{CH}_{3}\right] \rightarrow \mathrm{CH}_{2}=\mathrm{CHCH}_{2} \mathrm{CH}_{3} .
$$


It is of interest that the increase in the yield of 1 butene with photon energy parallels the increase in the yield of $n$-butane, which as we have shown above, is formed in a reaction sequence involving $\mathrm{H}$ atom addition to ethylene. The presence of deuterium labeled butenes other than $\mathrm{C}_{4} \mathrm{D}_{8}$ and $\mathrm{C}_{4} \mathrm{D}_{4} \mathrm{H}_{4}$ in the photolysis and radiolysis of $\mathrm{C}_{2} \mathrm{H}_{4}-\mathrm{C}_{2} \mathrm{D}_{4}$ mixtures might be explained by the participation of diffusive recombination of vinyl and ethyl radicals in the overall 1-butene production. Increased diffusion would explain the observation that butenes such as $\mathrm{C}_{4} \mathrm{H}_{7} \mathrm{D}, \mathrm{C}_{4} \mathrm{D}_{7} \mathrm{H}$, $\mathrm{CH}_{3} \mathrm{D}_{5}$, and $\mathrm{C}_{3} \mathrm{H}_{5} \mathrm{D}_{3}$ are formed at relatively higher yields in the liquid phase [3d] than in the solid phase radiolysis and that in the liquid phase they increase relative to the yields of $\mathrm{C}_{4} \mathrm{H}_{8}, \mathrm{C}_{4} \mathrm{H}_{4} \mathrm{D}_{4}$ and $\mathrm{C}_{4} \mathrm{D}_{8}$, with an increase in temperature [3d].

It is understood that proposed mechanism is a tentative one and that other mechanisms such as those proposed in previous studies cannot be ruled out.

Of the $\mathrm{C}_{4} \mathrm{H}_{8}$ products formed in the solid phase irradiations of ethylene (table 1 ) there is one product, cyclobutane, which seems to be formed via a $\mathrm{C}_{2} \mathrm{H}_{4}^{+}$ intermediate. This statement is based on the fact that the relative yield of cyclobutane is very small in the photolysis with $8.4 \mathrm{eV}$ photons where presumably few ions are formed (cyclobutane was not even detected in the earlier study [1] at this energy), and increases by nearly an order of magnitude when the photon energy is raised to $10.0 \mathrm{eV}$ and again increases when the energy is raised to $11.6-11.8 \mathrm{eV}$. This large increase in yield with energy can be contrasted with the yields of the butene products, which increase by less than a factor of two when the energy is augmented from $8.4 \mathrm{eV}$ to 11.6-11.8 eV. Furthermore, the fact that approximately 90 percent of the cyclobutane formed in the photolysis and radiolysis of $\mathrm{C}_{2} \mathrm{D}_{4}-\mathrm{C}_{2} \mathrm{H}_{4}$ mixtures consists of $\mathrm{C}_{4} \mathrm{H}_{8}, \mathrm{C}_{4} \mathrm{H}_{4} \mathrm{D}_{4}$, and $\mathrm{C}_{4} \mathrm{D}_{8}$ (see Results) indicates that this product is formed mainly in a reaction of $\mathrm{C}_{2} \mathrm{H}_{4}\left(\mathrm{C}_{2} \mathrm{D}_{4}\right)$ entities as has been shown before [3d] in the liquid phase radiolysis of ethylene.

Cyclobutane is also formed in the mercury photosensitized photolysis [18] of ethylene at a pressure of 700 torr, with a quantum yield of $3.8 \times 10^{-6}$. In those experiments, the cyclobutane product was suggested to be formed as a result of a reaction between triplet state ethylene and ground state ethylene:

$$
\begin{aligned}
& \mathrm{C}_{2} \mathrm{H}_{4}^{T}+\mathrm{C}_{2} \mathrm{H}_{4} \rightarrow\left(c-\mathrm{C}_{4} \mathrm{H}_{8}\right)^{*} \\
& \left(c-\mathrm{C}_{4} \mathrm{H}_{8}\right)^{*}+\mathrm{M} \rightarrow c-\mathrm{C}_{4} \mathrm{H}_{8}
\end{aligned}
$$

If, in the solid phase photolysis experiments, cyclobutane originates in reaction 14 we must conclude that the formation of triplet state ethylene is important only at photon energies higher than $8.4 \mathrm{eV}$. This could be explained if triplet state ethylene were formed in a neutralization reaction such as:

$$
\mathrm{C}_{2} \mathrm{H}_{4}^{+}+e \rightarrow \mathrm{C}_{2} \mathrm{H}_{4}^{T}
$$

In radiolysis, triplet ethylene may also be formed by direct excitation:

$$
\mathrm{C}_{2} \mathrm{H}_{4}+e \rightarrow \mathrm{C}_{2} \mathrm{H}_{4}^{T}+e .
$$

Cyclobutane has been reported [19] as a product $(G \sim 0.1)$ in the gas phase radiolysis of $\mathrm{C}_{2} \mathrm{H}_{4}$ (pressure: 100 torr) and ascribed to the participation of triplet ethylene. Reaction 17 cannot be operative in the 10 and $11.6 \mathrm{eV}$ photolysis experiments, since the ejected electrons will have insufficient energy to bring about the optically forbidden transition to the lowest triplet state at $3.6 \mathrm{eV}$ [20].

The 2-butenes are formed as minor products in all the solid phase irradiations given in table 1. Their yield shows little or no variation with increasing energy; hence, their formation is probably not associated with an ionic process. This is of interest, since, as indicated above, in the gas phase at pressures of 100 torr or less, it has been shown that reaction 10 of the ethylene ion with ethylene leads mainly to the formation of $2-\mathrm{C}_{4} \mathrm{H}_{8}^{+}$ions. Thus, at any rate, the absence of 2 butene as an important product in any of the solid phase experiments demonstrates that $\mathrm{C}_{4} \mathrm{H}_{8}^{+}$ions formed in reaction 10 do not undergo neutralization to form $2-\mathrm{C}_{4} \mathrm{H}_{8}$, under these conditions.

Methylcyclopropane is also formed in small yields in all the solid phase photolysis and radiolysis experiments reported in table 1 . In experiments carried out with $\mathrm{C}_{2} \mathrm{H}_{4}: \mathrm{C}_{2} \mathrm{D}_{4}(1: 1)$ mixtures, about $75-80$ percent of this product consists of $\mathrm{C}_{4} \mathrm{H}_{8}, \mathrm{C}_{4} \mathrm{H}_{4} \mathrm{D}_{4}$, or $\mathrm{C}_{4} \mathrm{D}_{8}$. In an earlier study [1] of the solid phase photolysis of ethylene at $8.4 \mathrm{eV}$, the formation of methylcyclopropane was attributed to a reaction of an ethylidene with ethylene:

$$
\mathrm{CH}_{3} \mathrm{CH}+\mathrm{C}_{2} \mathrm{H}_{4} \rightarrow c-\mathrm{C}_{3} \mathrm{H}_{5}\left(\mathrm{CH}_{3}\right) .
$$

Although this mechanism which requires a rearrangement of a long-lived excited ethylene molecule would indeed account for the isotopic distribution of methylcyclopropane products formed in the $\mathrm{C}_{2} \mathrm{H}_{4}: \mathrm{C}_{2} \mathrm{D}_{4}$ mixture, a free radical mechanism occurring in the cage may also explain the experimental observation. Addition of $\mathrm{CH}_{2} \mathrm{CH}$ to $\mathrm{C}_{2} \mathrm{H}_{4}$ occurs with a low activation energy $(0.14 \mathrm{eV})$ for thermal $\mathrm{CH}_{2} \mathrm{CH}$ radicals and may involve a neighboring molecule, especially if, as in the gas phase, the $\mathrm{CH}_{2} \mathrm{CH}$ retains some internal energy after its formation. Such an addition process would lead to the formation of the 3-butenyl radical [3f] and conceivably also of the methylene cyclopropyl radical. These two radicals may capture a neighboring hydrogen atom to form dimeric l-butene and methylcyclopropane respectively.

\subsection{The Formation of Cyclopropane}

The results given in table 1 show that cyclopropane is a product in all experiments. Since the addition of methylene to ethylene to form cyclopropane:

$$
\mathrm{CH}_{2}+\mathrm{C}_{2} \mathrm{H}_{4} \rightarrow c-\mathrm{C}_{3} \mathrm{H}_{6}
$$

is a well-known reaction [21], the presence of this product suggests that methylene is formed in the solid 
phase photolysis and radiolysis of ethylene. Indeed, the isotopic composition of the cyclopropane produced in the photolysis and radiolysis of a $\mathrm{C}_{2} \mathrm{H}_{4}: \mathrm{C}_{2} \mathrm{D}_{4}(1: 1)$ mixture (see Results) indicates that more than 80 percent of the cyclopropane consists of $c-\mathrm{C}_{3} \mathrm{H}_{6}$, $c-\mathrm{C}_{3} \mathrm{H}_{4} \mathrm{D}_{2}, \quad c-\mathrm{C}_{3} \mathrm{D}_{4} \mathrm{H}_{2}$, and $c-\mathrm{C}_{3} \mathrm{D}_{6}$. This distribution is consistent with the formation of cyclopropane through addition of $\mathrm{CH}_{2}\left(\mathrm{CD}_{2}\right)$ to $\mathrm{C}_{2} \mathrm{H}_{4}\left(\mathrm{C}_{2} \mathrm{D}_{4}\right)$. Insertion of a $\mathrm{CH}_{2}$ species into a $\mathrm{C}-\mathrm{H}$ bond of ethylene would also lead to the formation of propylene

$$
\mathrm{CH}_{2}+\mathrm{C}_{2} \mathrm{H}_{4} \rightarrow \mathrm{CH}_{3} \mathrm{CHCH}_{2} \text {. }
$$

Propylene is formed as a product in these experiments (table 1), but has not been analyzed isotopically.

If indeed the cyclopropane and propylene products can be assumed to result from reactions 19 and 20, we can infer the occurrence of the primary process:

$$
\mathrm{C}_{2} \mathrm{H}_{4}^{*} \rightarrow 2 \mathrm{CH}_{2} .
$$

This process requires less than $8.3 \mathrm{eV}$ [7a] so there is enough energy available even in the $8.4 \mathrm{eV}$ photolysis for its occurrence. It is seen that in the photolysis the relative importance of cyclopropane formation increases with increasing energy.

\subsection{The Formation of Hexenes}

Several $\mathrm{C}_{6} \mathrm{H}_{12}$ products are formed in the solid phase irradiations. The total yields of these products are listed in table 1.

The yields of the hexene products are relatively small in the $8.4 \mathrm{eV}$ photolysis, but undergo a large increase when the energy is raised to $10.0 \mathrm{eV}$, and more than double again when the energy is further raised to $11.6-11.8 \mathrm{eV}$. These observations are very similar to those made above concerning the yields of the cyclobutane product. As in that case, we can infer that the large increase in yield when the energy is raised to a point where ionization is certainly of importance (10.0 $\mathrm{eV}$ ) may be related to participation of ions in the formation of the products in question. It has been reported before [3c] that the 2-hexene product formed in the radiolysis of a $\mathrm{C}_{2} \mathrm{D}_{4}-\mathrm{C}_{2} \mathrm{H}_{4}(\mathrm{l}: \mathrm{l})$ mixture at $77 \mathrm{~K}$ consisted of more than 75 percent $\mathrm{C}_{6} \mathrm{H}_{12}, \mathrm{C}_{6} \mathrm{H}_{4} \mathrm{D}_{8}$, $\mathrm{C}_{6} \mathrm{H}_{8} \mathrm{D}_{4}$, and $\mathrm{C}_{6} \mathrm{D}_{12}$. In the present study (see Results) it is seen that the 2-hexenes, as well as the 1-hexene product have a similar isotopic composition when an equimolar ethylene mixture is irradiated with 11.6$11.8 \mathrm{eV}$ photons. That is, most of the hexene products are evidently made up of $\mathrm{C}_{2} \mathrm{H}_{4}\left(\mathrm{C}_{2} \mathrm{D}_{4}\right)$ units.

In the earlier radiolysis study [3c] it was suggested that hexene is formed in a process initiated by reaction of the $\mathrm{C}_{2} \mathrm{H}_{4}^{+}$ion with ethylene and terminated by electron recombination with a $\mathrm{C}_{6} \mathrm{H}_{12}^{+}$species. The present photolysis experiments seem to substantiate this interpretation. Especially if one considers that an electron scavenger such as $\mathrm{CCl}_{4}$ has a profound effect on the yields of the hexene (table 1). The actual role of $\mathrm{CCl}_{4}$ in the enhancement is uncertain. It is however of interest to note that the yields of the $\mathrm{C}_{4}$ products are not seriously affected by $\mathrm{CCl}_{4}$.

\section{References}

[1] Tschuikow-Roux, E., McNesby, J. R., Jackson, W. M., and Faris, J. L., J. Phys. Chem., 71, 1531 (1967).

[2] For a review see Holroyd, R., in Fundamental Processes in Radiation Chemistry, Ausloos, P., Ed. (1968).

[3] (a) Chang, P. C., Yang, N. C., and Wagner, C. D., J. Am. Chem. Soc. 81, 2060 (1959); (b) Collinson, E., Dainton, F. S., and Walker, D. C., Trans. Faraday Soc. 57, 1732 (1961); (c) Wagner, C. D., J. Phys. Chem. 66, 1158 (1962); (d) Holroyd, R. A., and Fessenden, R. W., J. Phys. Chem. 67, 2743 (1963); (e) Wagner, C. D., Trans. Faraday Soc. 64, 163 (1968); (f) Fessenden, R. W., and Schuler, R. H., J. Chem. Phys. 39, 2147 (1963); (g) Brash, J. L., and Golub, M. A., Can. J. Chem. 46, 593 (1968); (h) Klassen, N. V., J. Phys. Chem. 71, 2409 (1967); (i) Wagner, C. D., J. Phys. Chem. 71, 3445 (1967).

[4] Rebbert, R. E., and Ausloos, P., J. Chem. Phys. 46, 4333 (1967).

[5] Scala, A. A., and Ausloos, P., J. Chem. Phys. 47, 5129 (1967).

[6] Gorden, R., Jr., Rebbert, R. E., and Ausloos, P., Natl. Bur. Std. Technical Note 496 (1969).

[7] (a) Chupka, W. A., Berkowitz, J., and Refaey, K. M. A., J. Chem. Phys. 50, 1938 (1969); (b) Botter, R., Dibeler, V. H., Walker, J. A., and Rosenstock, H. M., J. Chem. Phys. 45, 1298 (1966); (c) Brehm, B., Z. Naturforschg. 2 la, 196 (1966); (d) Al-Joboury, M. I., and Turner, D. W., J. Chem. Soc., 4434 (1964).

[8] Vermeil, C., Matheson, M., Leach, S., and Muller, F., J. Chim. Phys. 34, 596 (1964).

[9] Gorden, R., Jr., and Ausloos, P., J. Chem. Phys. 47, 1799 (1967).

[10] Tiernan, T. O., and Futrell, J. H., J. Phys. Chem. 72, 3080 (1968).

[11] (a) Stevenson, P., Rad. Res. 10, 610 (1959); (b) Ausloos, P., and Lias, S. G., Actions Chimiques et Biologiques des Radiation, 11, 1 (1967).

[12] (a) Sauer, M. C., and Dorfman, L. M., J. Chem. Phys. 35, 497 (1961); (b) Okabe, H., and McNesby, J. R., J. Chem. Phys. 36, 601 (1962); (c) Ausloos, P., and Gorden, R., Jr., J. Chem. Phys. 36, 5 (1962).

[13] Back, R. A., and Griffiths, D. W. L., J. Chem. Phys. 46, 4839 (1967); and Borrell, P., Cashmore, P., Cervenka, A., and James, F. C., J. Chim. Phys. 229 (1970).

[14] Sieck, L. W., in Fundamental Processes in Radiation Chemistry Ausloos, P., Ed. (1968).

[15] Ausloos, P., Rebbert, R. E., and Sieck, L. W., J. Chem. Phys. in press and references cited therein.

[16] Meisels, G. G., J. Chem. Phys. 42,3237 (1965).

[17] Ausloos, P., Structure and Reactivity of Hydrocarbon Ions in Ion-Molecule Reaction, J. L. Franklin, Ed. (Plenum Press, 1971).

[18] Chesick, J. P., J. Am. Chem. Soc. 85, 3718 (1963).

[19] Meisels, G. G., J. Am. Chem. Soc. 87,950 (1965).

[20] Evans, D. F., J. Chem. Soc. 1351 (1957); 1735 (1960).

[21] Frey, H. M., Progr. Reaction Kin. 2, 131 (1964).

(Paper 75A3-657) 